\title{
Long-term solar UV radiation reconstructed by ANN modelling with emphasis on spatial characteristics of input data
}

\author{
U. Feister ${ }^{1}$, J. Junk ${ }^{2}$, M. Woldt ${ }^{3}$, A. Bais ${ }^{4}$, A. Helbig ${ }^{5}$, M. Janouch ${ }^{6}$, W. Josefsson ${ }^{7}$, A. Kazantzidis ${ }^{4}$, A. Lindfors ${ }^{8}$, \\ P. N. den Outer ${ }^{9}$, and H. Slaper ${ }^{9}$ \\ ${ }^{1}$ Deutscher Wetterdienst, Richard Aßmann Observatorium Lindenberg, Am Observatorium 12, 15848 Lindenberg, Germany \\ ${ }^{2}$ Public Research Centre - Gabriel Lippmann, Department of Environment and Agro-Biotechnologies (EVA), 41, rue du Bril, \\ 4422 Belvaux Grand-Duchy of Luxembourg, Luxembourg \\ ${ }^{3}$ Brandenburgische Techn. Univ. Cottbus, Lehrstuhl für Umweltmeteorologie, Burger Chaussee 2, 03044 Cottbus, Germany \\ ${ }^{4}$ Aristotle University of Thessaloniki, Laboratory of Atmospheric Physics, 54124, Thessaloniki, Greece \\ ${ }^{5}$ Universität Trier, Fachbereich VI, Fach Umweltmeteorologie, 54286 Trier, Germany \\ ${ }^{6}$ Solar and Ozone Observatory, Czech Hydrometeorological Inst., Hvezdarna 456, 50008 Hradec Kralove 8, Czech Republic \\ ${ }^{7}$ Swedish Meteorological and Hydrological Institute, 60176, Norrköping, Sweden \\ ${ }^{8}$ Finnish Meteorological Institute, P.O. BOX 503 (Erik Palmenin aukio 1), 00101 Helsinki, Finland \\ ${ }^{9}$ National Institute for Public Health and the Environment, A. van Leeuwenhoeklaan 9, P.O. Box 1, 3720 BA Bilthoven, \\ The Netherlands
}

Received: 4 December 2007 - Published in Atmos. Chem. Phys. Discuss.: 10 January 2008

Revised: 20 May 2008 - Accepted: 20 May 2008 - Published: 23 June 2008

\begin{abstract}
Artificial Neural Networks (ANN) are efficient tools to derive solar UV radiation from measured meteorological parameters such as global radiation, aerosol optical depths and atmospheric column ozone. The ANN model has been tested with different combinations of data from the two sites Potsdam and Lindenberg, and used to reconstruct solar UV radiation at eight European sites by more than 100 years into the past. Special emphasis will be given to the discussion of small-scale characteristics of input data to the ANN model.

Annual totals of UV radiation derived from reconstructed daily UV values reflect interannual variations and long-term patterns that are compatible with variabilities and changes of measured input data, in particular global dimming by about 1980/1990, subsequent global brightening, volcanic eruption effects such as that of Mt. Pinatubo, and the long-term ozone decline since the 1970s. Patterns of annual erythemal UV radiation are very similar at sites located at latitudes close to each other, but different patterns occur between UV radiation at sites in different latitude regions.
\end{abstract}

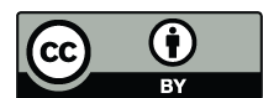

Correspondence to: U. Feister (uwe.feister@dwd.de)

\section{Introduction}

Reconstruction of solar global UV radiation for the past decades has gained scientific interest, because regular spectral UV radiation measurements started only less than two decades ago in the 1990s (Bais and Lubin, 2007). For the reconstruction of UV radiation, models can be used that simulate the radiative transfer of solar radiation on its way through the atmosphere, in particular by simulation of scattering and absorption of radiation by atmospheric gases and particles using physically-based laws and parameterizations, or - as a different approach that has been applied in this study - by statistical relations between UV radiation and those atmospheric parameters that are closely related to UV radiation, and have been measured over long time periods. Due to the lack of appropriate microphysical and macrophysical cloud input data, radiative transfer models are often applied in a mixed mode, i.e. clear sky UV irradiance is modeled, and the cloud effect subsequently accounted for by cloud modification factors derived from measured global radiation data.

Based on experience with an earlier approach that used a non-linear statistical model to reconstruct solar UV radiation (Feister et al., 2002), Artificial Neural Networks (ANN) have been used in this study. The ANN are capable of simulating even highly non-linear and complex relationships between

Published by Copernicus Publications on behalf of the European Geosciences Union. 
an arbitrary number of input data (predictors), and between input and output data (predictands), and are therefore commonly applied in different fields of science (Chevallier et al., 1998, Oliveira et al., 2006). It is one of the advantages of this method that the relationship between input data and output data does not need to be pre-defined or a-priori known. This implies that physical laws, parameterizations of atmospheric processes, or empirical relations derived from experiments can be neglected, because they are implicitly derived from the variability and covariance between input and output parameters by the training of the ANN. Therefore, assumptions on the input parameters that have usually not been measured in the past such as aerosol and cloud characteristics (optical depths, single scattering albedo, phase functions, size distributions etc.) need not be made in the ANN, because the complex relationship between the input parameters and UV radiation will be simulated and "learned" by the ANN in the training process. On the other hand, a suitable sample size of concurrent input and output data that covers their typical variability in time - and if applied in the spatial domain, in space - is needed to finally provide small uncertainties of the ANN model output. It is another advantage of the ANN that model performance and reliability may be further improved by re-training such that changes in the statistical distribution and types of atmospheric conditions that did not occur in the first training period are accounted for in the improved ANN model version.

ANN models can be applied to any number of input parameters including geographic parameters such as latitude and height above sea level, provided that adequate training samples of data are available. Examples of the siteindependent use of ANN for the reconstruction of UV radiation that illustrate this feature have been shown in an earlier study (Feister and Junk, 2006). An advantage of ANN compared to some other statistical modelling approaches is their capability of not being bound to a certain type of statistical distribution of data. Therefore, tests on the statistical distribution functions of input and output parameters have not been performed in this study.

Our study will focus on the description of the data used, including small-scale spatial characteristics that have been derived from data at two sites with small spatial distance, briefly describe the ANN method, discuss the uncertainties of reconstructed UV irradiation, and finally show general features and patterns of reconstructed UV irradiation at different European sites for more than 100 years.

\section{Input data}

\subsection{UV radiation}

Predictands in this study are daily totals of erythemal UV irradiation. The erythemal action spectrum is based on the weighting function by CIE (1987). For two sites, where the needed input data have been available, integrated daily UV irradiation in the regions UV-B (280-315 nm) and UV-A (315$400 \mathrm{~nm}$ ) has also been reconstructed.

Erythemal radiation has been selected as a target parameter in our study, because it is most commonly used in the public as UV index, and daily doses of erythemal radiation can be used to derive monthly and annual doses, and are thus appropriate to study longer-term effects of solar radiation to the environment. Daily erythemal irradiation had been selected as the target parameter within the European action COST 726 "Long term changes and climatology of UV radiation over Europe" and in the European project SCOUT-O3, in which both processing and analysis of input data at the two sites Potsdam and Lindenberg as well as the ANN modelling have been embedded. Reconstruction models including the ANN model would generally allow for higher time resolution than daily values, for example hourly values to show diurnal patterns, but the non-availability of input data at smaller than daily time steps in the decades before the 1970s would have required assumptions on their diurnal changes.

Broad-band UV radiation was either integrated from spectral solar irradiance measured by different types of spectroradiometers, or directly measured by broad-band UV filter radiometers. As we are focusing on two close sites in this study, Table 1 shows an overview of the UV radiation data for those sites Potsdam and Lindenberg, in particular, the instruments used, their spectral range, step width, full bandwidth at half maximum (FBHM), the method used to extend spectra to the wavelength of $400 \mathrm{~nm}$, the number of spectra per day, the method of cosine correction, calibration sources of instruments, and the method of frequent calibration checks.

\subsubsection{Brewer spectra at Potsdam}

UV irradiance at the Meteorological Observatory Potsdam $\left(52^{\circ} 22^{\prime} \mathrm{N}, 13^{\circ} 5^{\prime} \mathrm{E}, 107 \mathrm{~m}\right.$ a.s.l. $)$ was measured by Brewer spectroradiometers (\#030 MKII, and \#118 MKIII) from 1995 to April 2003 about one to two times per hour. As the Brewer spectra extend only to $325 \mathrm{~nm}$ (\#030) or $363 \mathrm{~nm}$ (\#118), spectral irradiance up to $400 \mathrm{~nm}$, which is needed to derive UV-A and erythemal irradiance, was derived by the algorithm of Slaper et al. 1995. Calibration of the instruments was based on Secondary Standard Lamps of the type DXW $1000 \mathrm{~W}$ (tungsten halogen) that were calibrated once to two times per year from Primary Standard Lamps of the type FEL $1000 \mathrm{~W}$ Osram Sylvania calibrated at Physikalisch-Technische Bundesanstalt (PTB). The cosine error of the Brewer instruments was accounted for by a correction applied to the measured Brewer spectra by estimating the components of direct and diffuse irradiance from measured global UV irradiance with the help of "spectral optical depths" that were derived from concurrent broad-band UV filter radiometer measurements, and application of the cosine correction to the radiation components (Feister et al., 1997). This method of cosine correction takes the effect of cloud conditions on UV irradiance 
Table 1. Instruments, time periods, wavelength range, wavelength steps, extension of spectra to $400 \mathrm{~nm}$, number of spectra per day, method of cosine correction, calibration and calibration checks of spectroradiometers at the sites Potsdam (A) and Lindenberg (B).

\begin{tabular}{|c|c|c|c|c|c|c|c|c|c|}
\hline Site & Instr. No. & Period & Range(nm) & Steps $(\mathrm{nm})$ & Extension & Spectra per day & Cosine correction & Calibration & Checks \\
\hline \multirow[t]{2}{*}{ A } & $\begin{array}{l}\text { Brewer MKII } \\
\# 30\end{array}$ & $\begin{array}{l}01 / 1995 \text { to } \\
04 / 2003\end{array}$ & 290 to 325 & 0.5 & $\begin{array}{l}\text { Slaper et al. } \\
(1995)\end{array}$ & 9 to 18 & $\begin{array}{l}\text { Feister et al. } \\
\text { (1997) }\end{array}$ & $\begin{array}{l}\text { DXW } 1000 \mathrm{~W} \text { based } \\
\text { on FEL } 1000 \text { from PTB }\end{array}$ & $\begin{array}{l}50 \mathrm{~W} \\
\text { Brewer lamps }\end{array}$ \\
\hline & $\begin{array}{l}\text { Brewer MKIII } \\
\# 118\end{array}$ & $\begin{array}{l}1996 \text { to } \\
2003\end{array}$ & 290 to 363 & 0.5 & ditto & 9 to 18 & ditto & ditto & ditto \\
\hline \multirow[t]{2}{*}{ B } & $\begin{array}{l}\text { Brewer MKIV } \\
\# 78\end{array}$ & $\begin{array}{l}01 / 1995 \text { to } \\
12 / 2004\end{array}$ & 290 to 325 & 0.5 & $\begin{array}{l}\text { Slaper et al. } \\
(1995)\end{array}$ & 9 to 18 & $\begin{array}{l}\text { Bais et al. } \\
(2005)\end{array}$ & $\begin{array}{l}\text { International } \\
\text { Ozone Services }\end{array}$ & $\begin{array}{l}50 \mathrm{~W} \\
\text { Brewer lamps }\end{array}$ \\
\hline & SPECTRO 320D & $\begin{array}{l}01 / 2005 \text { to } \\
07 / 2007\end{array}$ & 290 to 450 & 0.2 & not needed & 450 to 1000 & not needed & FEL $1000 \mathrm{~W}$ from PTB & $\begin{array}{l}200 \mathrm{~W} \text { KS03 } \\
\text { Metzdorf et al. } \\
(2003)\end{array}$ \\
\hline
\end{tabular}

during the time of the Brewer scan (5 to $8 \mathrm{~min}$ ) into account. For the purpose of comparison, but not as part of the data base for modelling, UV radiation values were also derived from spectra measured with a Bentham DM 150 instrument Spectral scans that are taken every 6 min between sunrise and sunset, cover the wavelength region 290 to $450 \mathrm{~nm}$, and the instrument's calibration is based on $1000 \mathrm{~W}$ FEL lamps traceable to PTB.

\subsubsection{Brewer spectra at Lindenberg}

Spectral UV irradiance at Lindenberg $\left(52^{\circ} 12^{\prime} 31^{\prime \prime} \mathrm{N}\right.$, $14^{\circ} 7^{\prime} 17^{\prime \prime} \mathrm{E}, 127 \mathrm{~m}$ a.s.1.) has been measured since 1995 by Brewer spectroradiometer \#078 (MKIV). The instrument was calibrated in August 1994 by an FEL 1000 W lamp (Nagel and Leiterer, 1995), and about annually thereafter by International Ozone Services (IOS) with either $50 \mathrm{~W}$ or DXW $1000 \mathrm{~W}$ lamps. The calibration report of August 29-31, 1996 mentions that the Brewer \#078 response files were found $9 \%$ low in 1996, and that a forward correction of the files, but no backward correction had been applied. Therefore, the Brewer UV values were increased for our study for the period $01 / 1995$ to $08 / 1996$ by $9 \%$. Further annual instrument calibrations by IOS in the period between 1997 and 2003 reported differences and forward corrections of UV response files by less than 4 to $5 \%$.

UV spectra of instrument \#078 had not been corrected for cosine errors of the instrument at the site. The method of cosine correction applied to Brewer instruments \#030 and \#118 at Potsdam could not be used, because the required concurrent broad-band UV radiation data were not available at Lindenberg. Therefore, the cosine correction method described by Bais et al. (2005) that does not require additional measured input data was kindly applied by A. Kazantzidis and A. Bais to the all UV spectra of Brewer instrument \#078 between 1995 and 2004.

From 2005 onwards spectral irradiances taken by fastscanning spectroradiometers of the type SPECTRO 320D were used (Feister et al., 2005). Calibrations of those instruments have been based on lamps of the type FEL $1000 \mathrm{~W}$ that were calibrated by PTB with a stated absolute uncertainty of $\pm 3 \%$. On-site checks of calibration levels have been performed monthly by a $200 \mathrm{~W}$ lamp with ventilated housing (Metzdorf et al., 2003). Due to the improved characteristics of the instrument's cosine diffuser, a cosine correction to spectral irradiances has not been applied. Spectral coverage from 290 to $450 \mathrm{~nm}$ with an oversampling stepwidth of $0.2 \mathrm{~nm}$ did not require a spectral extension. Spectral scans, which take about $23 \mathrm{~s}$ each, are taken every minute. Every three hours the instrument's dark current is measured and removed from the raw data.

\subsubsection{Hourly and daily UV irradiation}

Hourly and daily broad-band UV irradiation can be derived from the individual broad-band data by summing up individual irradiances. For the one-minute time steps of SPECTRO 320D data, the short-term variability of UV irradiance is correctly reflected in the hourly and daily doses. However, for the non-equidistant longer time steps of Brewer data, assumptions on the variability of UV irradiance between two subsequent scans need to be taken. If the variability is not taken into account, the additional uncertainty of hourly totals of erythemal UV radiation derived from UV irradiances that are measured at sampling time steps of $30 \mathrm{~min}$ was found to be 3 to $6 \%$ with sunny conditions, and 16 to $29 \%$ with all weather conditions (Feister et al., 2005).

In addition to geographical factors determining solar zenith angle and station-height above sea level, as well as absorption by atmospheric ozone, UV irradiance is affected by scattering of solar radiation

- due to clouds via their macrophysical features such as cloud cover, cloud optical depth, cloud pattern, cloud vertical extension, and cloud distance to the apparent position of the sun (in particular, if they occlude direct beam radiation), and also via microphysical attributes such as type, size, and distribution of cloud droplets or particles, 


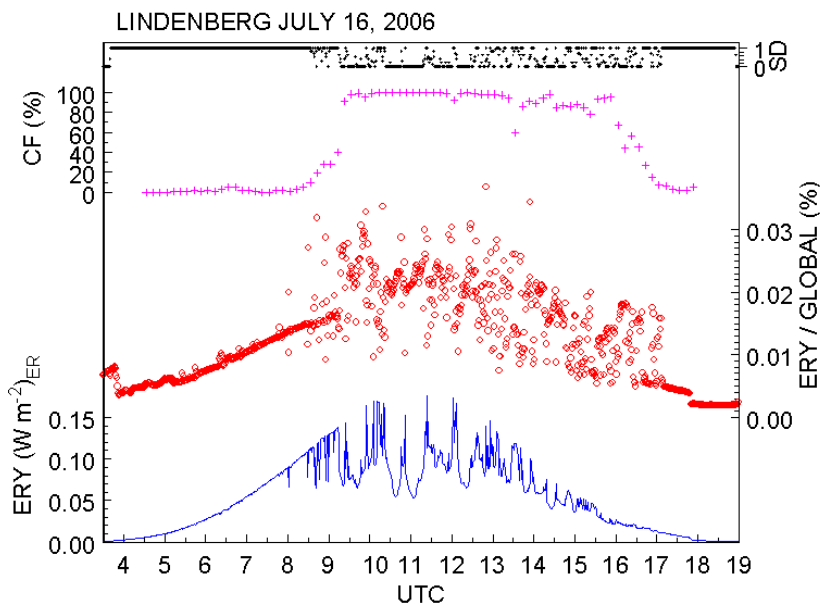

Fig. 1. Erythemal UV irradiance ERY from SPECTRO 320D measurements (lower panel), ratios between UV irradiance and global irradiance UV/G (second from bottom), cloud fraction in per cent (CF) derived form Whole Sky Imager measurements (third from bottom), and sunshine duration in fractions per minute (upper panel) on 16 July 2006 at Lindenberg.

- due to the type and features of aerosols (optical depth, size distribution, single scattering albedo, phase function, etc.) and

- due to the albedo of the ground, especially the occurrence of snow.

Global irradiance in the visible (VIS) and near infrared (NIR) region is also scattered, though with different wavelength dependence and to a different extent. In addition, water absorption plays a role for global irradiance. If fast front passages or drifting pollutant plumes are excluded, atmospheric conditions typically change on time scales of hours. Fast changes within minutes down to seconds do occur for changing cloud patterns, cloud optical depths and clouds occluding or not occluding the sun. In addition, diurnal variations of ratios between clear sky UV and global irradiance show a typical pattern with increasing values towards noon time and decreasing values in the afternoon, and higher values with cloudy conditions.

An example of the varying ratios UV/G for 16 July 2006 is shown in Fig. 1.

Concurrent cloud fraction (CF) derived from Whole Sky Imager measurements shows that the short-term variability of $\mathrm{UV} / \mathrm{G}$ ratios is not correlated to CF, which is close to $100 \%$ between about 10:00 and 16:00 UTC, but is mainly due to varying cloud optical depths, and the position of clouds occluding or not occluding the sun, as is illustrated in Fig. 1 by the one-minute values of sunshine duration (SD). We used the ratios UV/G to derive hourly and daily totals of UV radiation to account for the short-term variability between spectral UV scans. For that purpose, global irradiances available at time steps of one minute were averaged over the time in-

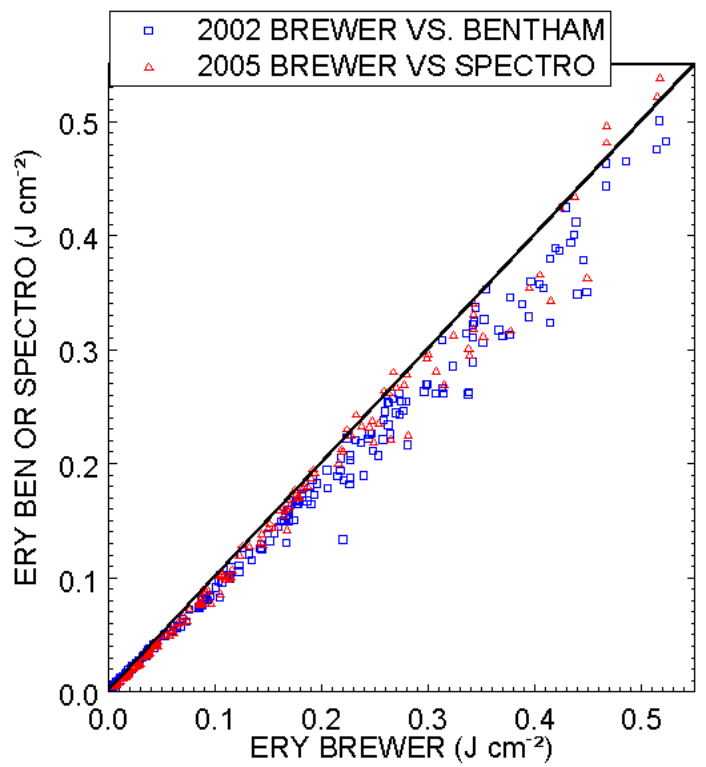

Fig. 2. Daily erythemal UV irradiation derived from Brewer spectra compared to those derived from Bentham spectra at Potsdam in 2002, and SPECTRO 320D spectra at Lindenberg in 2005.

tervals of UV scans. The UV/G ratios were assumed to be constant between two consecutive UV scans, and the broadband UV irradiance between the UV scans was estimated from ratios between measured UV and measured global irradiances, and summed up to hourly and daily totals. Therefore, both the dependence on solar zenith angle and the shortterm cloud variability is taken into account for hourly and daily UV radiation totals. This approach was applied to derive daily UV irradiation at Potsdam and Lindenberg only. Different methods to derive daily totals of erythemal radiation may have been applied at the other sites by the data providers.

A comparison between daily erythemal irradiation derived from Brewer measurements by this method, and daily values derived from Bentham spectra that are available at time steps of $6 \mathrm{~min}$ at Potsdam for the year 2002, and from SPECTRO $320 \mathrm{D}$ spectra measured at one-minute time steps for the year 2005 is shown in Fig. 2.

Differences between daily erythemal irradiation values are due to remaining uncertainties of the method used to derive daily totals from Brewer data, the spectral extension of Brewer spectra to $400 \mathrm{~nm}$, the uncertainties of measurements with different types of instruments resulting especially from remaining uncertainties of cosine corrections (Brewer spectra) and absolute calibration uncertainties, atmospheric variabilities and non-coincidence in scan-time duration and time steps between spectral scans, and finally uncertainties due to missing data and filling larger data gaps. On an annual average over the respective time periods, the overall differences between daily erythemal irradiation from Brewer measurements and Bentham or SPECTRO 320D data amount to 
about $-7 \%$ and $-2 \%$, respectively. The uncertainty of daily erythemal UV irradiation from Brewer spectra as described above was estimated to be about 12 to $14 \%$.

\subsection{Meteorological predictors}

An advantage of neural networks is their capability of selecting the best combination of available predictors. Different sets of meteorological input data have been tentatively used as predictors. Not only their correlation with UV irradiation, but also their daily and long-term availability, representativeness of typical atmospheric conditions, and rate of change are important in the selection of potential parameters. Cloud cover observations have been performed for many decades. Unfortunately, cloud observations in the early days were restricted to three times per day. Aerosol optical depths (AOD) have been measured at Potsdam and Lindenberg. AOD measurements at Potsdam were performed within a small range of solar zenith angles between about $85^{\circ}$ and $75^{\circ}$ only. Therefore, diurnal courses and thus daily averages could not be derived for that site. For both sites, AOD measurements are not available on overcast days, i.e. for about $50 \%$ of the days. Therefore, AOD has not been used as predictor for the ANN model. We note that information on cloud variability and aerosol extinction is contained in global and diffuse irradiation. Snow depth was used a predictor, though due the very few days with snow cover, its effect at lowlevels sites in Central Europe is small in most cases. Depending on the availability of input data over certain time periods in the past, different versions or training sets of neural networks were chosen. The following parameters were finally used as predictors in this study: global and diffuse irradiation, sunshine duration, column ozone, horizontal visibility, snow height, surface albedo, cloud cover, and minimum solar zenith (SZA) angle of the day, as well as number of the month.

\subsection{Short and long-term variability of data}

The distance of only $73 \mathrm{~km}$ between the two sites Potsdam and Lindenberg provides a chance to look at small-scale features of input parameters, and also to check their overall consistency. Figure 3 shows a scatter plot of daily erythemal irradiation derived from Brewer measurements at Potsdam as compared to Lindenberg.

There is a close correlation of 0.97 for all cases, and a still higher correlation of 0.99 for "sunny" cases, where the latter are defined here by the condition of ratios between daily diffuse and global irradiation of less than 0.5. Most of the outliers in the scatter plots occur for cloudy cases, the extremes of which are circled in Fig. 3. As a results of the uncertainties mentioned in Sect. 2.1, the average difference between daily erythemal irradiation values derived from Brewer data between Lindenberg and Potsdam over the whole time period is $6 \%$ to $7 \%$. This value does not necessarily mean that

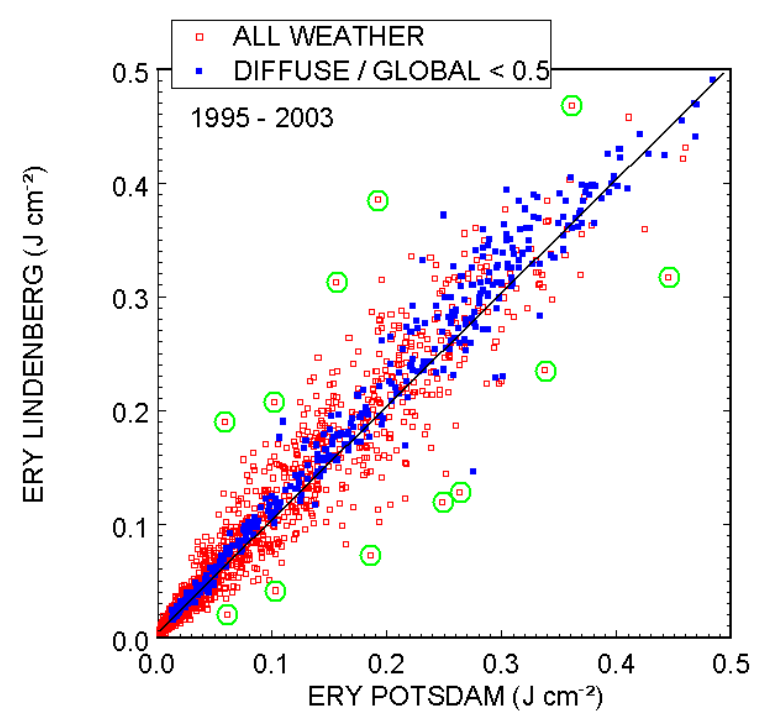

Fig. 3. Daily erythemal irradiation at Potsdam as compared to Lindenberg over the period 1995 to 2003 for all-weather conditions and "sunny" conditions. The latter are defined here by ratios between daily diffuse and global irradiation of less than 0.5. Extreme cases are circled.

there has been a constant systematic difference, because the individual differences are highly variable over time. We also note that the differences are within the stated uncertainties of the daily UV values derived from the measurements.

Small-scale differences in air quality may have also contributed to the differences in erythemal UV radiation between the two sites. Potsdam located SSW of the city of Berlin is closer to pollution sources of the large city than Lindenberg, which is SE and about $50 \mathrm{~km}$ from the city. In addition to transport of polluted plumes from local sources, long-range transport of anthropogenic aerosols as well as regional biogenic sources may have also contributed to aerosol concentrations at the sites. Averages of aerosol optical depths at SZA around $80^{\circ}$ and at a wavelength of $550 \mathrm{~nm}$ over the period 1995-2003 show only slightly different values of 0.164 and 0.166 , respectively, at the two sites. These values do not contain diurnal AOD variations that would be relevant for effects on daily UV radiation. However, looking at the scatter plot between monthly mean AOD values at the two sites, for AOD values higher than about 0.2 , there is a tendency of AOD being higher by about 0.05 to 0.1 at Potsdam than at Lindenberg. We are aware that due to neglecting diurnal variations and due to the limited number of observations (availability for about $50 \%$ of all days), these results need not necessarily reflect average conditions that are relevant for the record of daily UV radiation, but they may be an indication that small-scale variations of aerosol extinction can have contributed to the differences in daily UV irradiation at the two sites.

Percentage ratios, as shown in Fig. 4, between daily erythemal and global radiation at Potsdam compared to Lindenberg, reveal that the extreme differences circled in Fig. 3 are 


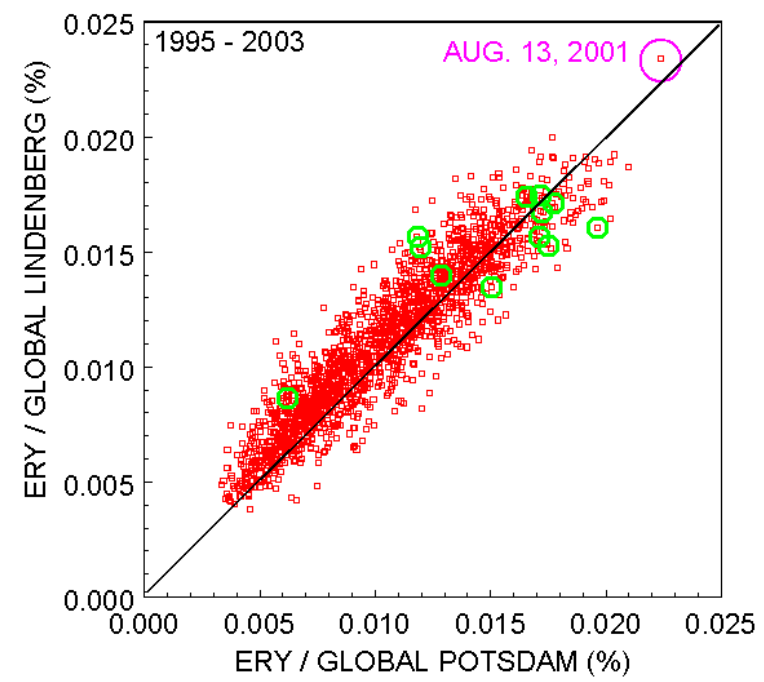

Fig. 4. Percentage ratios between daily erythemal and global irradiation at Potsdam compared to those at Lindenberg in the period 1995 to 2003. The same extreme cases as in Fig. 3 are circled.

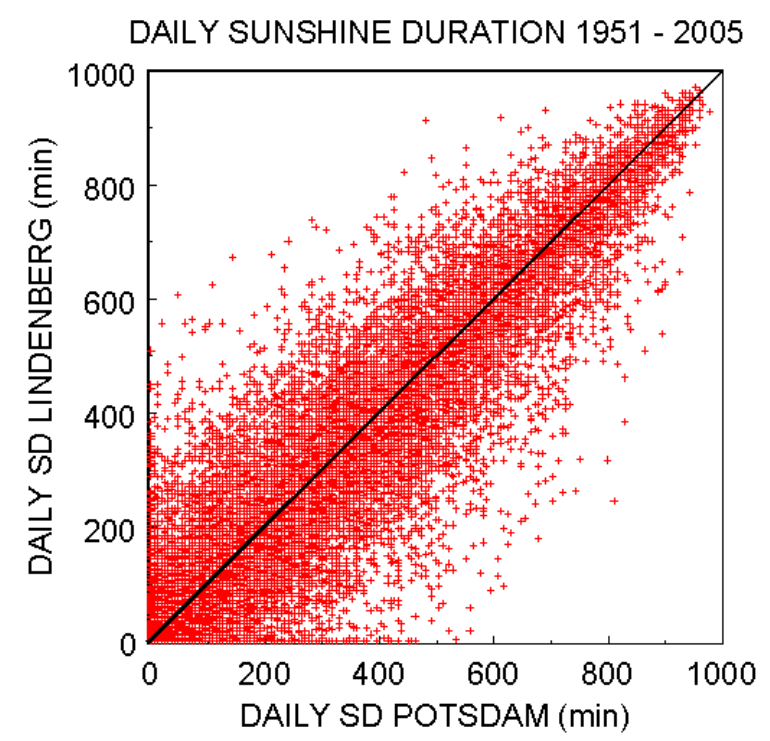

Fig. 5. Daily sunshine duration at Potsdam as compared to Lindenberg in the period 1951 to 2005.

no outliers any more. This implies that they are mainly due to different cloud conditions prevailing for most of the time during the respective days at the two sites. The highest ratio between erythemal and global irradiation at both sites occurred on a dim day (13 August 2001) with 8 Okta of Sc during the whole day, and very small values of daily global irradiation of $363 \mathrm{~J} \mathrm{~cm}^{-2}$ at Potsdam and $452 \mathrm{~J} \mathrm{~cm}^{-2}$ at Lindenberg.

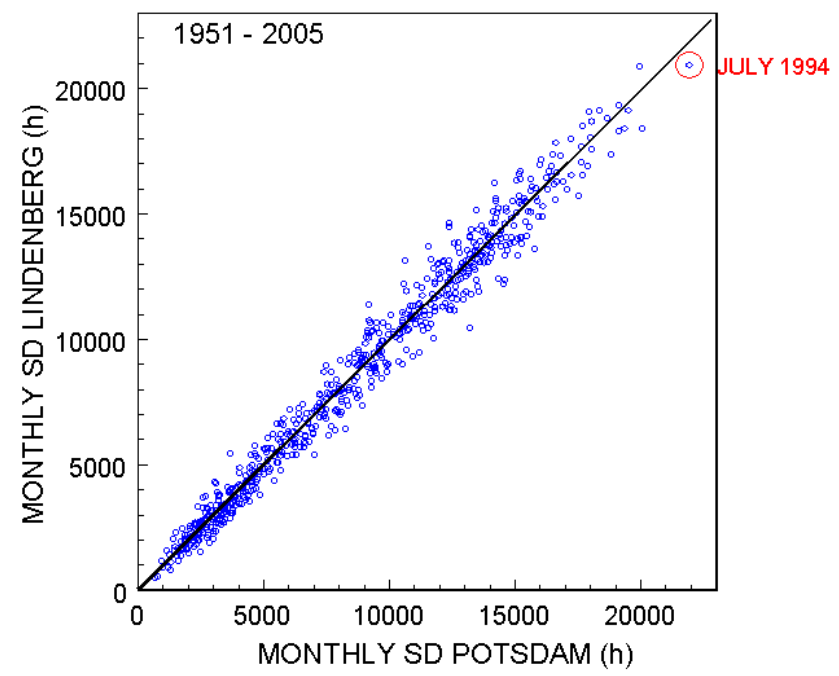

Fig. 6. Monthly sunshine duration at Potsdam as compared to Lindenberg in the period 1951 to 2005.

An input parameter with highly small-scale features is sunshine duration. Figure 5, which compares daily sunshine duration of Potsdam and Lindenberg, shows a strong scatter, although the correlation coefficient of 0.93 is already high. If we look at monthly values of sunshine duration, the scatter between sunshine duration at both sites is much smaller, as is shown in Fig. 6, and the correlation coefficient with 0.99 is still higher.

Different to sunshine duration, atmospheric column ozone varies on much larger spatial scales, as is shown in Fig. 7. Therefore, ozone values at both sites show a close correspondence in the majority of cases, but in some cases larger differences can be observed that may occur at times of frontal passages, or that may be due smaller scale stratospheric patterns.

The monthly mean ozone values in Fig. 8 show the seasonal ozone variation and long-term changes as well as short-term effects from volcano eruptions as in 1963 (Mt. Agung/Indonesia), 1982 (El Chichon/Mexico) and 1991 (Mt. Pinatubo/Philippines) that the ANN must cope with and that should be reflected in the reconstructed erythemal und UV-B radiation.

\section{Reconstruction of UV irradiation by Artificial Neural Networks (ANN)}

\subsection{The ANN method}

A neural network imitates the human brain's own problem solving capability. It applies knowledge gained from past experience and previously solved examples to new problems or situations by building a system of "neurons" that takes new decisions and provides predictions. In this project, the 


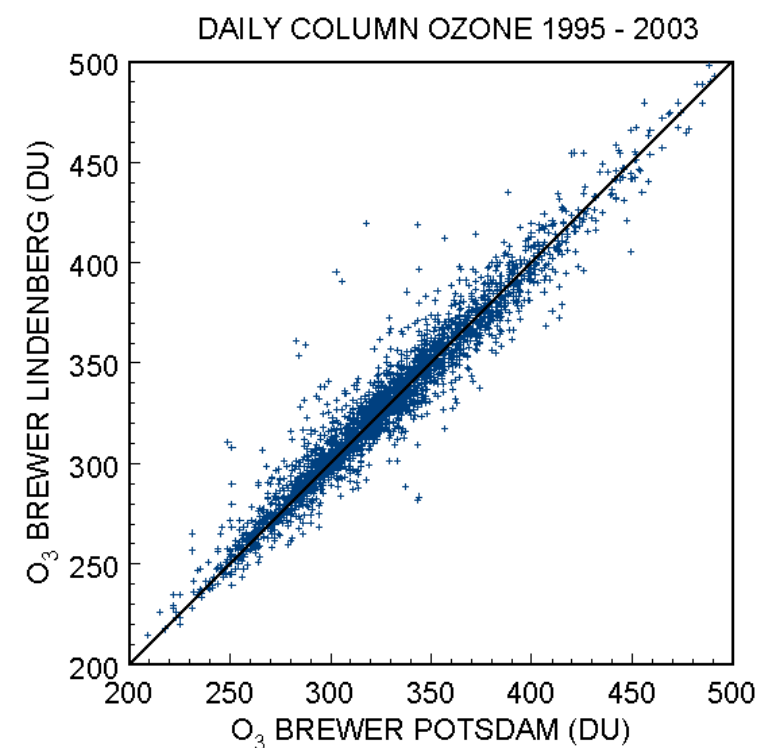

Fig. 7. Daily column ozone at Potsdam as compared to Lindenberg in the period 1995 to 2003 .

NeuroShell 2 software, release 4 by Ward Systems Group, Inc. has been used to design different neural network versions for each set or combination of input parameters. In addition to the advantages of ANN discussed in Sect. 1, it needs to be taken into account that all features of the input data, i.e. not only the complex atmospheric variability, but also errors and uncertainties of measurements, for example cosine errors of UV radiation measurements or errors in the UV radiation dose values used for training, will be transferred to the ANN, and can be reflected in the model results. More details on the ANN method as it is applied here were discussed by Junk et al. (2007).

Input data of the ANN are connected to output data by hidden layers. Each data set consisting of measured daily UV irradiation and a combination of predictors was divided into a training set ( $70 \%$ of the data), a production set $(15 \%$ of the data), and a test set (15\% of the data). Due to the interrelation between predictors, each combination of input data that covers a certain time period at a site had to be trained separately.

Table 2 shows that 10 predictors and 6 combinations of input data were selected according to their availability over certain time periods at the Potsdam site. When going back in time, the number of input parameters becomes smaller. Also shown are the resulting uncertainties (bias and RMS) in reconstructed daily UV irradiation in dependence of the ANN version. It can be seen in Table 2 that the most pronounced RMS increases occur, if "important" predictors are left, such as for column ozone (between ANN\#3 and ANN\#4), and global and diffuse radiation (between ANN\#1 and ANN\#2). If global and diffuse irradiation values are available, the RMS between measured and reconstructed UV irradiation is be-

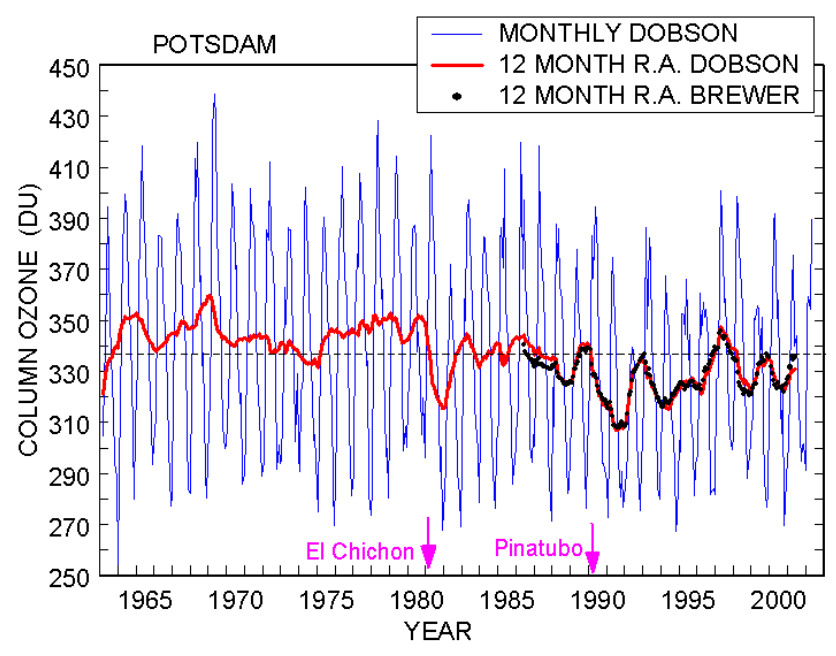

Fig. 8. Monthly mean column ozone from Dobson observations as well as 12 months running averages of Dobson and Brewer ozone data at Potsdam.

tween $11 \%$ and $17 \%$. It increases to the range of $16 \%$ to $22 \%$, if sunshine duration is the only measured input parameter, in addition to month and minimum solar zenith angle. With the relative standard deviation of daily UV irradiation of between $75 \%$ and $95 \%$, even the ANN versions using a small set of input parameters and resultant higher uncertainties do provide a gain of information on the day-to day variation of solar UV irradiation as compared to the use of climatological averages.

It might be argued that ANN \#1, which was applied over the first decades at the Potsdam site when no other measured input parameters were available, may have led to a smaller spatial representativity of reconstructed daily UV irradition, because daily sunshine duration, as shown by the scatter plot in Fig. 5, is a small-scale phenomenon. However, if longer time periods such as monthly totals are concerned, its spatial correlation is much higher, and the reconstructed monthly and annual UV irradiation will therefore be representative for a larger area (Fig. 6). We also note that the characteristics of the variability of input parameters in space and time will be modified within the ANN such that the variation of output parameters in space and time can substantially differ from that of the input parameters. The scatter plots of daily reconstructed UV irradiation at Potsdam and Lindenberg do show patterns of much closer correlation more similar to that of measured values as shown in Fig. 3 .

\subsection{Sensitivity tests}

A few sensitivity tests were performed to illustrate the effect of variations of input parameters to the reconstructed UV radiation. Cloud effects on the reconstruction can be seen in Fig. 9 that shows a scatter plot between measured and reconstructed erythemal irradiation at Potsdam for cases with 
Table 2. Selected predictors for time periods and resulting uncertainties of different ANN versions for the site Potsdam. A is the percentage bias, and B the percentage RMS between measured and reconstructed daily UV-A, UV-B and erythemal irradiation with test data set.

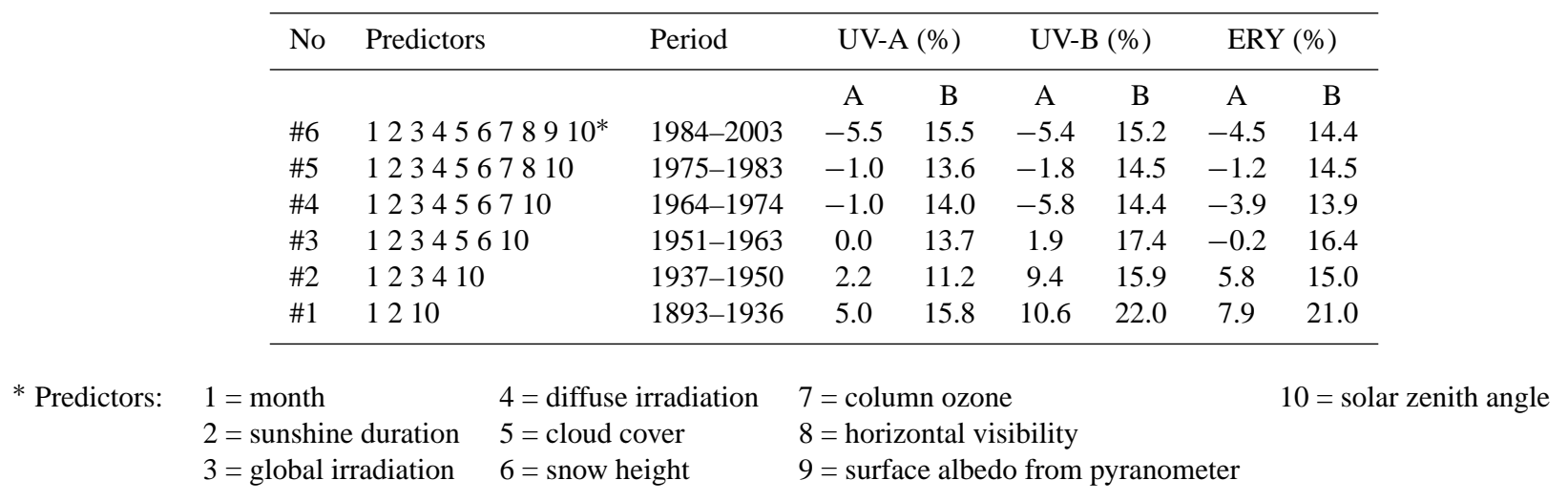

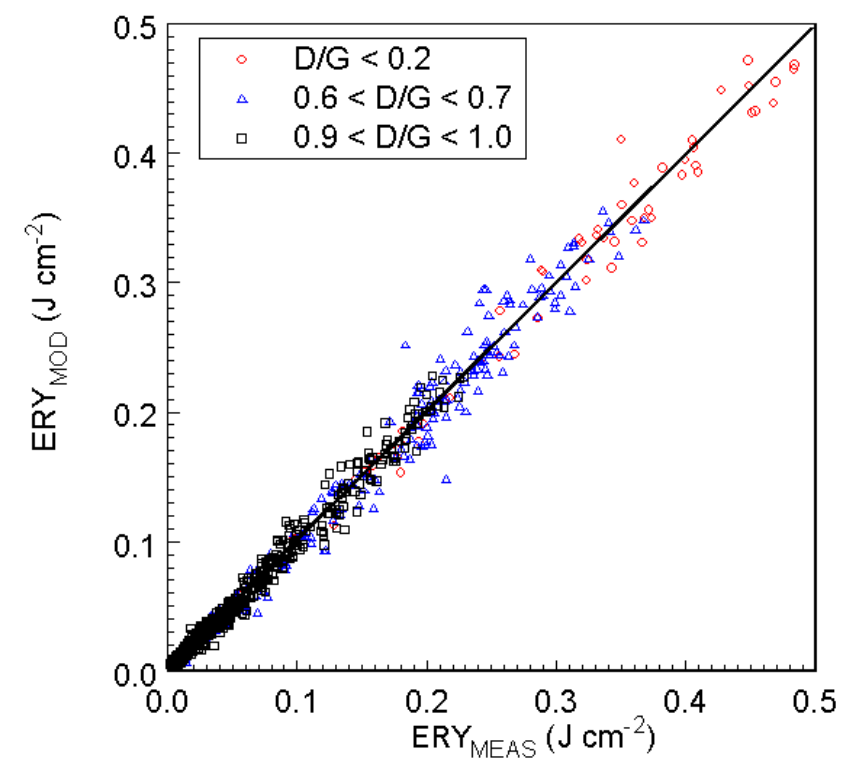

Fig. 9. Measured and reconstructed daily erythemal irradiation at Potsdam 1995-2003 for ratios between diffuse and global irradiation of less than 0.2 (sunny conditions), 0.6 to 0.7 (cloudy), and 0.9 to 1 (overcast or heavy cloudy).

sunny, cloudy and overcast (or heavy cloudy) conditions, as defined by ratios between daily diffuse and global irradiation. A cloud effect on the reconstruction quality is not obvious in Fig. 9.

The effect of changing column ozone to UV-B and erythemal radiation in individual months for ozone amounts changed by $-20 \%,-10 \%, \ldots,+10 \%,+20 \%$ is shown in Fig. 10. As is reasonable, the ozone effect is negligible for UV-A radiation. For erythemal irradiation, an ozone change of $10 \%$ results in a change of about $10 \%$, and of between $5 \%$ to $20 \%$ for UV-B irradiation. The latter shows a more pronounced seasonal dependence with a higher effect in the
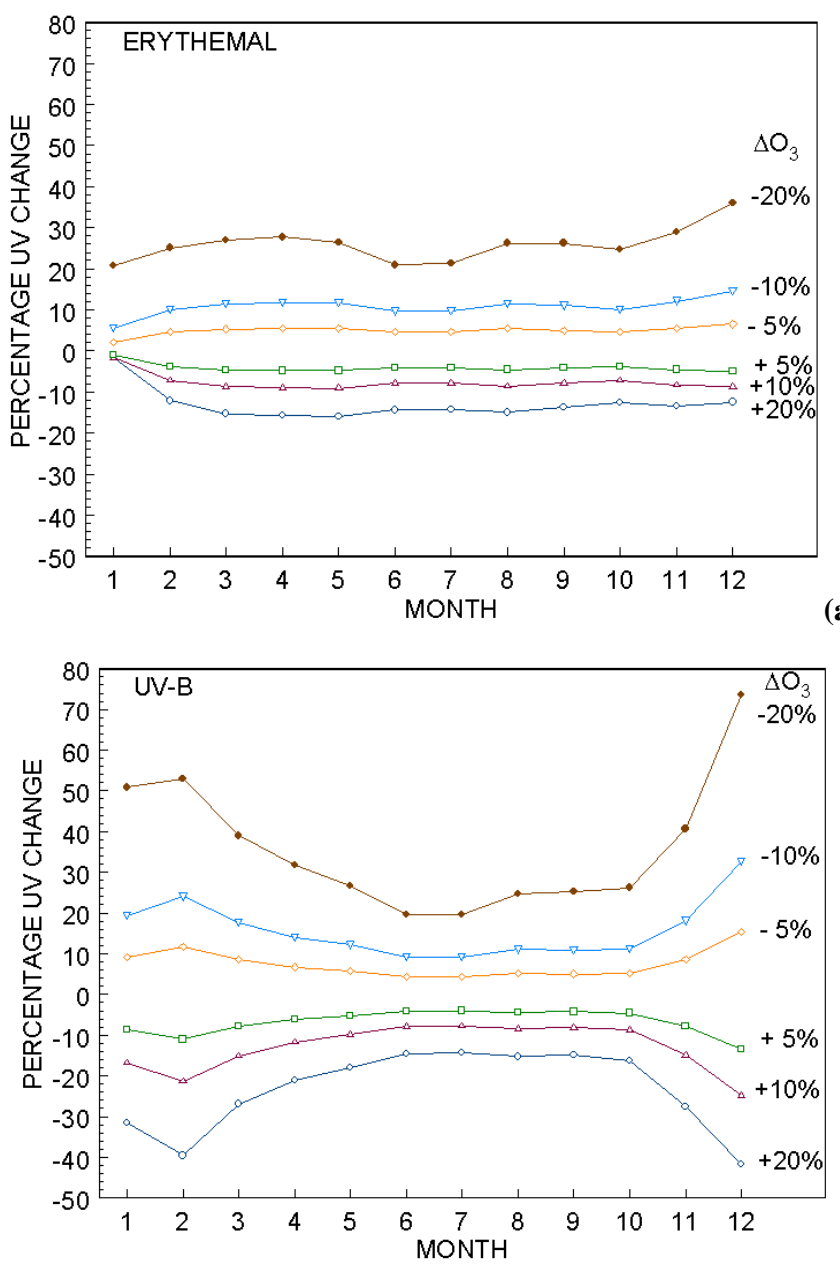

(b)

Fig. 10. Percentage difference between reconstructed erythemal (a) and UV-B (b) between average column ozone and ozone changed by amounts between $-20 \%$ and $+20 \%$. 


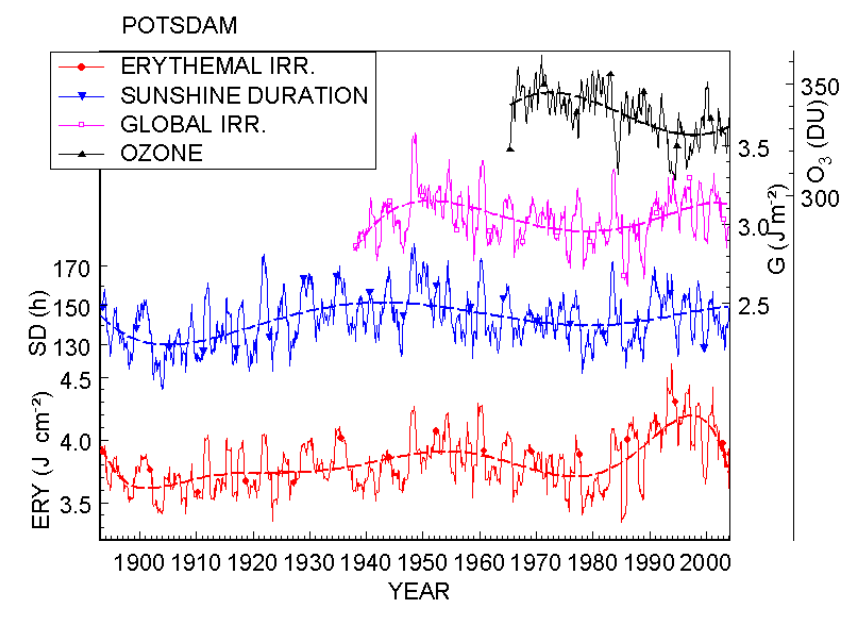

Fig. 11. 12-months running averages of monthly values of reconstructed erythemal irradiation (ERY, lower panel), measured values of sunshine duration (SD, second from bottom), global irradiation ( $\mathrm{G}$, third from bottom) and column ozone $\left(\mathrm{O}_{3}\right.$, upper panel) at Potsdam over the period 1893 to 2003. Dashed curves are polynomial fittings to show long-term variations.

winter months, and smaller values in summer than erythemal radiation.

A third test showed that the use of climatological averages of daily column ozone values instead of neglecting ozone as a predictor does not significantly improve the reconstruction of erythemal UV radiation. This result is somewhat surprising, because the seasonal ozone variation at mid-latitudes is comparable or even higher than its general day-to day variability. On the other hand, the sensitivity test was performed with data of the period 1995-2003. As can be seen in Fig. 8, due to the reduced ozone values after the Mt. Pinatubo eruption in 1991 and the long-term ozone decline since about 1970, the seasonal ozone variation at the end of the last century and beginning of the present century appears to be somewhat smaller compared to earlier years before that period.

\section{Results}

\subsection{Reconstructed UV radiation at Potsdam}

Using the different ANN versions for the time periods, daily UV irradiation was reconstructed backwards in time. Figure 11 shows the reconstructed erythemal irradiation together with measured sunshine duration, global radiation and column ozone for the site Potsdam in the period 1893 to 2003. In this plot, monthly running averages were derived from the reconstructed daily values to remove the seasonal variation, and better reveal long-term features in the data records. Systematic differences according to Table 2 were removed from the re-constructed UV data for the respective time periods. It would have been preferable to remove the systematic de-

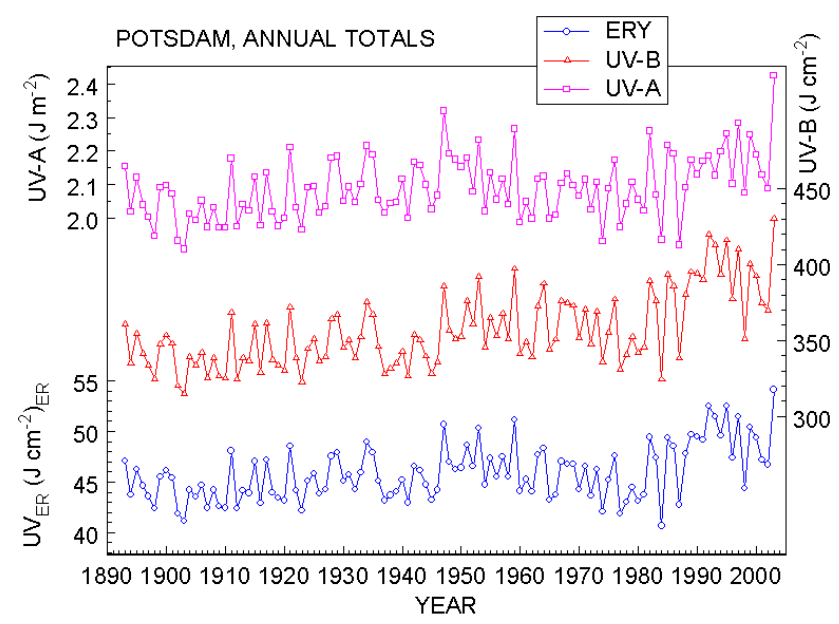

Fig. 12. Annual totals of reconstructed erythemal, UV-B and UV-A irradiation at Potsdam from 1893 to 2003.

viations in the ANN training process, though tests runs with removed systematic deviations showed that the ANN would have provided worse results of daily irradiation, and thus higher RMS values in extreme situations. Therefore, the bias was removed only after reconstruction.

In addition to running averages, polynomial fits have been added just to show more clearly long-term variations. They are not meant to be optimum statistical estimates. Longterm effects such as the "global dimming" effect between about 1960 and 1990 (Ohmura and Lang 1989) and the subsequent increase known as "global brightening" (Wild et al. 2005) that are also obvious in measured global radiation, and the decline of atmospheric ozone since about 1970, as well as the effect of the Mt. Pinatubo aerosols on ozone in the 1990s are reflected in the reconstructed erythemal radiation. Lowest vales of sunshine duration can be noticed in the first decade of the 20th century. Though it remains to be speculative, a connection to volcanic eruptions cannot be excluded that occurred in Central America in 1902. The volcanoes Mount Pelée $\left(14.82^{\circ} \mathrm{N}, 61.17^{\circ} \mathrm{W}\right)$ on Martinique island and Soufrière on Saint Piere $\left(13.33^{\circ} \mathrm{N}, 61.18^{\circ} \mathrm{W}\right)$ erupted shortly one after the other in May 1902. Those eruptions were followed by the eruption of Santa Maria $\left(14.76^{\circ} \mathrm{N}\right.$, $91.55^{\circ} \mathrm{W}$ ) in Guatemala in October 1902 (Kelly et al., 1996). The ash cloud of the latter volcano with a volcanic explosivity index (VEI) of 6 reached a height of $28 \mathrm{~km}$, and was comparable in magnitude with that of the Mt. Pinatubo eruption in 1991.

Annual totals of reconstructed erythemal, UV-B and UVA radiation for the whole period 1893 to 2003 are shown in Fig. 12. The systematic deviations mentioned in Table 2 for the different ANN versions and thus certain time periods were also removed from the values of irradiation.

Relative, percentage deviations from the overall mean values (1983-2003) for erythemal, UV-B and UV-A are shown 
Table 3. Correlation coefficients between measured daily erythemal and global irradiation $R_{\mathrm{ERY}} \mathrm{G}$, relative (percentage) standard deviations of measured daily erythemal irradiation (RSTD), and root mean square differences (RMS) between ANN modelled and measured daily erythemal irradiation at different sites. Gain of information by reconstruction with the ANN model is shown in the last column.

\begin{tabular}{lcccc}
\hline Site & $R_{\text {ERY_G }}$ & RSTD(\%) & RMS(\%) & $(1-R M S) / R S T D * 100(\%)$ \\
\hline Sodankylä & 0.945 & 76.9 & 10.9 & 86 \\
Jokioinen & 0.961 & 76.4 & 8.9 & 88 \\
Norrköping & 0.968 & 102.8 & 8.2 & 92 \\
Potsdam & 0.957 & 95.5 & 14.4 & 85 \\
Lindenberg & 0.963 & 95.6 & 8.4 & 91 \\
Bilthoven & 0.964 & 89.3 & 12.5 & 86 \\
Hradec Kralove & 0.960 & 91.9 & 13.1 & 86 \\
Thessaloniki & 0.961 & 61.1 & 6.6 & 89 \\
\hline
\end{tabular}

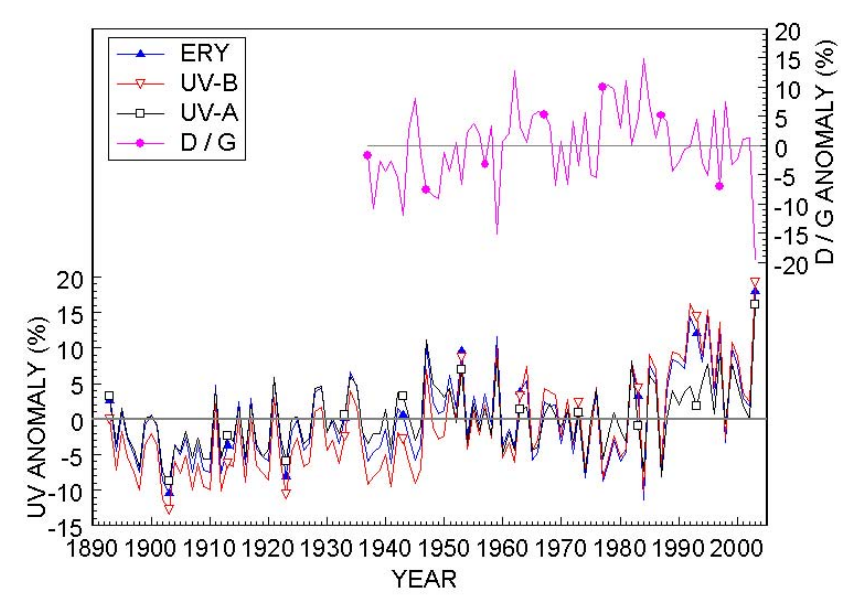

Fig. 13. Anomalies, i.e. annual totals of reconstructed UV irradiation, for erythemal, UV-B and UV-A referred to their overall mean values (lower panel), and anomalies of measured diffuse to global radiation (upper panel) at Potsdam.

in Fig. 13. UV radiation increases by a few per cent by the middle of the 1930s, and drops to low values in the 1940s. After a higher peak in the second half of the 1940s, UV radiation slowly decreases by the second half of the 1980s by a few per cent. This latter decrease of UV radiation may have been a results of increasing cloud cover and/or cloud optical depths and the effect of aerosols. The upper panel of Fig. 13 shows the ratios of diffuse to global radiation that increase from the end of the 1930s to the middle of the 1980s by about 10 to $15 \%$, and decrease by about the same amount in the years thereafter, probably as a result of changing cloud cover. The UV increase beginning at the end of the 1970s seems to be mainly the result of decreasing cloudiness that affected all three components. The additional effect of low ozone values in the 1990s led to an additional enhancement of UV-B and erythemal radiation by about 5 to $10 \%$ in the 1990 s in correspondence to earlier estimates (Feister and Grewe, 1995).

\subsection{Reconstructed UV radiation at European sites}

The ANN model was applied to data measured at other sites that have been collected and made available through the European SCOUT-O3 project and the COST 726 action. Overviews of the site input data sets as well as the results of comparisons between different modelling approaches are given by Josefsson (2006), Koepke at al. (2006), and den Outer et al. (2008).

Different sets of input data were available for 8 European sites at latitudes between $41^{\circ} \mathrm{N}$ and $67^{\circ} \mathrm{N}$ over different time periods. Training of the ANN was performed with different combinations of each site's input data needed for the reconstruction over certain time periods in the past. According to the focus of this study to get optimum reconstruction results for the past at each site, a site-independent approach was not applied, as was shown to be possible in an earlier study (Feister and Junk, 2006).

Table 3 shows the relative RMS differences between modeled and measured daily values of erythemal radiation that range from $7 \%$ to $14 \%$. If the RMS differences between modelled and measured UV irradiation at the individual sites are referred to the standard deviations of measured erythemal irradiation, which are different at the sites, the resulting gain of information by using the ANN model is more similar at the sites than the RMS differences. Those gain values shown in the last column of Table 3 are between $85 \%$ and $92 \%$.

Also shown in Table 3 are the correlation coefficients between measured daily erythemal and global irradiation at the individual sites. It can be seen that the highest value of 0.968 occurs for Norrköping, and the lowest value of 0.945 for Sodankylä. Lindenberg and Potsdam rank at positions 3 and 7, respectively. We conclude from this result that the use of oneminute values of global irradiance to derive daily UV irradiation from Brewer measurements at Potsdam and Lindenberg according to the method described in Sect. 2.1.3 has not led to a significantly higher correlation between daily UV and $G$ as compared to the UV to G correlations at other sites, and therefore, a substantial increase of the dependence between 


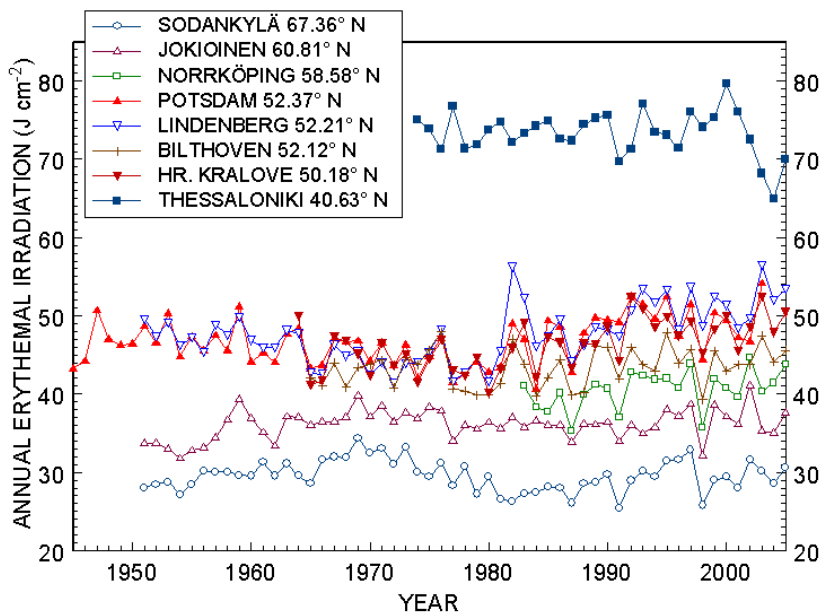

Fig. 14. Annual erythemal irradiation reconstructed by the ANN method for the sites Sodankylä/Finland $\left(67.36^{\circ} \mathrm{N}, 26.63^{\circ} \mathrm{E}\right)$, Jokioinen/Finland $\left(60.81^{\circ} \mathrm{N}, 23.49^{\circ} \mathrm{E}\right), \quad$ Norrköping/Sweden $\left(58.58^{\circ} \mathrm{N}, 16.15^{\circ} \mathrm{E}\right)$, Potsdam/Germany $\left(52.37^{\circ} \mathrm{N}, 13.08^{\circ} \mathrm{E}\right)$, Lindenberg/Germany $\left(52.21^{\circ} \mathrm{N}, 14.12^{\circ} \mathrm{E}\right)$, Bilthoven/The Netherlands $\left(52.12^{\circ} \mathrm{N}, 5.19^{\circ} \mathrm{E}\right)$, Hradec Kralove/Czech Republic $\left(50.18^{\circ} \mathrm{N}\right.$, $\left.15.83^{\circ} \mathrm{E}\right)$, and Thessaloniki/Greece $\left(40.63^{\circ} \mathrm{N}, 22.95^{\circ} \mathrm{E}\right)$.

input parameters $(\mathrm{G})$ and UV target values in the ANN data sets should not have occurred.

An overview of the variation of reconstructed erythemal irradiation in space and time is shown in Fig. 14. Annual totals were derived from monthly totals that were summed up from the reconstructed daily totals. If values of 1 to 2 days were missing, the gaps were filled by linear interpolation. For 3 to 7 missing daily totals, the monthly mean value of the same month was included to derive the monthly total, while for more than 7 days of missing data, long-term monthly averages were included to derive annual totals of UV radiation.

The reconstructed records of erythemal UV radiation show long-term patterns and interannual variations that reveal both similarities and differences. First, a latitudinal gradient can be seen that is mainly due to geographical differences determining solar zenith angle and day length. This effect combined with differences in cloudiness and the influence of other contributors leads to annual erythemal radiation that is for example at Thessaloniki $\left(41^{\circ} \mathrm{N}\right)$ about 2.5 as much as in Sodankylä $\left(67^{\circ} \mathrm{N}\right)$. The four sites Bilthoven, Hradec Kralove, Lindenberg and Potsdam with small latitudinal differences in Central Europe show very similar long-term patterns, and even similar interannual variations in annual erythemal UV that can be more clearly seen in Fig. 15 showing the percentage annual anomalies derived from the annual totals referring to the overall mean values at the individual sites. The long-term decrease between the 1950s and about 1980 is followed by a subsequent increase at the four sites. Opposite to the Central European sites, the sites in Finland show increasing values in the period between 1951 and the end of the 1960s, and a long-term behavior similar to the sites

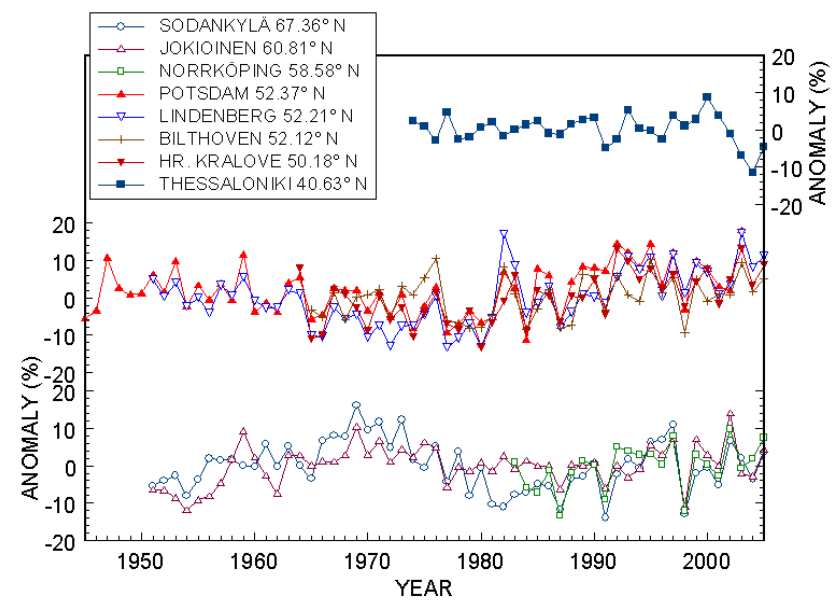

Fig. 15. Relative anomalies referred to the sites' overall averages of annual total erythemal radiation.

in Central Europe in the remaining period. Reconstructed erythemal radiation at the Southern European site Thessaloniki seems to have slightly increased between 1974 and 2000. This increase appears to be smaller than at the other sites, and UV radiation shows a strong decrease afterwards. Similarly, the short-term variation of annual erythemal radiation at Thessaloniki is different to that at the other sites. While some strong peaks such as the one in 1998 occur at all sites in Central and Northern Europe, the Greek site does not show any similarity. This difference may be explained by the different amount and different effect of clouds to UV radiation in the summer months.

\section{Conclusions}

Application and use of the ANN model for the reconstruction of daily solar UV irradiation has shown that this method is capable of modelling the complex relationship between broad-band solar UV radiation and meteorological input data. Modelled daily totals of solar UV were used to derive monthly and annual doses that show interannual and decadal long-term UV variations compatible with corresponding variations of input parameters, for example global dimming, global brightening, the UV effect of long-term ozone decline, and the pulse-type effects of volcanic eruptions to the atmosphere. It was also shown that the ANN model has to cope with variabilities of input parameters on different scales in space and time, and modify their effects such that reasonable variations of reconstructed UV irradiation are provided.

Independent application of the ANN method to 8 different sites spread across Europe shows a gain of information for modelled UV radiation at all sites, as compared to using average values as the only source of information. A remarkable correspondence referring to patterns of long-term 
changes and even interannual variability of reconstructed UV radiation has been found for sites located close in geographical latitude, while larger differences occur between the sites located at latitudes more than about $1000 \mathrm{~km}$ apart.

Acknowledgements. The support given by the European project SCOUT-O3 and the European activity COST 726 is greatly acknowledged. We thank all the data providers of the individual European sites for making available the relevant UV data and meteorological data that have been a prerequisite of our modelling exercise.

Edited by: J. Groebner

\section{References}

Bais, A., Kazantzidis, A., Kazadzis, S., and Kouremeti, N.: Application of a model derived cosine correction method on Brewer spectral measurements. European Geosciences Union, Vienna, 24-29 April 2005, Geophys. Res. Abstr., 7, 07590, 2005.

Bais, A. F. and Lubin, D.: Surface Ultraviolet Radiation: Past, Present, and Future, Scientific Assessment of Ozone Depletion: 2006, WMO Global Ozone Research and Monitoring Project, Report No. 50, 7.1-7.54, 2007.

Chevallier, F., Chéruy, F., Scott, N. A., and Chédin, A.: A Neural Network Approach for a Fast and Accurate Computation of a Longwave Radiative Budget, J. Appl. Meteorol., 37, 1385-1397, 1998.

CIE: A reference action spectrum for ultraviolet induced erythema in human skin, CIE Journal, 6, 17-22, 1987.

den Outer, P. N., Slaper, H., Lindfors, A., Kaurola, J., Bais, A., Kazantzidis, A., Feister, U., Junk, J., and Janouch, M.: Best estimate construction for historical UV using models and measurements, Annual SCOUT-O3 meeting, Potsdam, Germany, 21-24 April, 43-20, 2008.

Feister, U. and Grewe, R.: Higher UV radiation inferred from low ozone levels at northern mid-latitudes in 1992 and 1993, Global Planet. Change, 11, 25-34, 1995.

Feister, U., Grewe, R., and Gericke, K.: A method for correction of cosine errors in measurements of spectral UV irradiance, Sol. Energy, 60(6), 313-332, 1997.

Feister, U., Jäkel, E., and Gericke, K.: Parameterization of daily solar global ultraviolet irradiation, Photochem. Photobiol., 76, 281-293, 2002.

Feister, U. and Junk, J.: Reconstruction of daily solar UV irradiation by an Artificial Neural Network, SPIE, 6362-94, 63622H, 1-11, 2006.
Feister, U., Kaifel, A., Grewe, R.-D., Kaptur, J., Reutter, O., Wohlfart, M., and Gericke, K.: Fast measurements of solar spectral irradiance - first performance results of two novel spectroradiometers, Opt. Eng., 44(4), 041007-1-041007-9, 2005.

Josefsson, W.: UV-radiation 1983-2003 measured in Norrköping Sweden, Theor. Appl. Climatol., 83(1-4), 5976, doi:10.1007/s704-005-0160-1, 2006.

Junk, J., Feister, U., and Helbig, A.: Reconstruction of daily solar UV irradiation from 1893 to 2002 in Potsdam, Germany, Int. J. Biometeorol. 51, 505-512, 2007.

Kelly, P. M, Jones, P. D., and Pengqun, J.: The spatial response of the climate system to explosive volcanic eruptions, Int. J. Climatol., 16, 537-550, 1996.

Koepke, P., Debacker, H., Bais, A., Curylo, A., Eerme, K., Feister, U., Johnsen, B., Junk, J., Krzyscin, J., Lindfors, A., Olseth, J. A., den Outer, P., Pribullova, A., Schmalwieser, A. W., Slaper, H., Staiger, H., Verdebout, J., Vuilleumier, L., and Weihs, P.: Modelling solar UV radiation in the past: comparison of algorithms and input data. Remote Sensing of Clouds and the Atmosphere X1, SPIE, 6362-42, 636215-1-6362-15-11, 2006.

Metzdorf, J., Stock, K. D., Sperfeld, P., Sperling, A., Winter, S., and Wittchen, T.: Aspects of quality assurance in monitoring solar UV irradiance, Metrologia, 40, 66-69, 2003.

Nagel, D. and Leiterer, U.: Brewer Spektrophotometer MK IV: BMFT-Projekt "Optische Feldmessmethoden" , Abschlussbericht, Deutscher Wetterdienst, Abt. Forschung 22, Offenbach am Main, Germany, 1995.

Ohmura, A., and Lang, H.: Secular variation of global radiation in Europe, in: IRS '88: current Problems in Atmospheric Radiation, edited by: Lenoble, J. and Geleyn, J.-F., A. Deepak Publ., Hampton, VA, USA, 298-301, 1989.

Oliveira, A. P., Soares, J., Božnar, M. Z., Mlakar, P., and Escobedo, J. F.: An Application of Neural Network Technique to Correct the Dome Temperature Effects on Pyrgeometer Measurements, J. Atmos. Oceanic Technol., 23, 80-89, 2006.

Slaper, H., Reinen, A. J. M., Blumthaler, M., Huber, M., and Kuik, F.: Comparing ground-level spectrally resolved solar UV measurements using various instruments: a technique resolving effects of of wavelength shift and slit width, Geophys. Res. Lett. 22, 2721-2724, 1995.

Wild, M., Gilgen, H., Roesch, A., Ohmura, A., Long, C. N., Dutton, E. G., Forgan, B., Kallis, A., Russak, V., and Tsvetkov, A.: From dimming to brightening: Decadal changes in solar radiation at Earth's surface, Science, 308, 847-850, 2005. 